\title{
Clinico-laboratory profile of breath-holding spells in children in Sohag University Hospital, Upper Egypt
}

Abdelrahim Abdrabou Sadek ${ }^{1}$, Montaser Mohamed Mohamed ${ }^{2}$, El-Zahraa El-Said Ahmed Sharaf ${ }^{3}$, Rofaida Mohamed Magdy ${ }^{4}$, Ahmed Ahmed Allam ${ }^{5}$

${ }^{1}$ Assistant professor and head of Pediatric Neurology Unit, Department of Pediatrics, Faculty of Medicine, Sohag University, Sohag, Egypt

${ }^{2}$ Lecturer, Pediatric Neurology Unit, Department of Pediatrics, Faculty of Medicine, Sohag University, Sohag, Egypt

3 Professor and head of Pediatric Hematology Unit, Department of Pediatrics, Faculty of Medicine, Sohag University, Sohag, Egypt

${ }^{4}$ Assistant lecturer, Neurology Unit, Department of Pediatrics, Faculty of Medicine, Sohag University, Sohag, Egypt

${ }^{5}$ Ahmed Ahmed Allam; Lecturer, Department of Clinical Pathology, Faculty of Medicine, Sohag University, Sohag, Egypt

\section{Type of article: Original}

\begin{abstract}
Introduction: Breath-holding spells (BHSs) are involuntary pauses of breathing, sometimes accompanied by loss of consciousness. They usually occur in response to an upsetting or surprising situation. Breath-holding spells are usually caused by either a change in the usual breathing pattern or a slowing of the heart rate. In some children, BHSs may be related to iron deficiency anemia. The aim of the work was to study the clinical and laboratory profile of BPHs in children presented to the Neuropediatric Clinic at Sohag University Hospital.

Methods: An observational prospective study was done at Sohag University Hospital over a period of one year on children diagnosed as having BHSs by clinical history and laboratory evaluation, including complete blood count (CBC), serum iron, serum ferritin, total iron binding capacity, and Electroencephalography (EEG).

Results: During the period of study (one year), we reviewed data of 32 children who had been diagnosed as having BHSs. We found that cyanotic spells $(71.88 \%)$ predominated over pallid spells. There were positive family histories $(31.25 \%)$ and consanguinity $(53.135)$ in the studied patients. We found a high incidence of iron deficiency anemia (62.5\%) in association with BHS. Abnormal EEGs were found in $(65.63 \%)$ of studied children.

Conclusion: BHS is a common, important problem associated with iron deficiency anemia, which is, in turn, a common nutritional problem in our country.

Keywords: breath holding spells, cyanotic spells, pallid spells, iron deficiency anemia
\end{abstract}

\section{Introduction}

A breath-holding spell is an involuntary pause in breathing, sometimes accompanied by loss of consciousness. It usually occurs in response to an upsetting or surprising situation (1). Breath-holding spells occur in $5 \%$ of otherwise healthy children. They can occur in children between six months and six years of age, but they vary in how often they occur and how severe they are. Some children have them once a year, while others may have several spells within one day (2). Breath-holding spells usually are caused by either a change in the usual breathing pattern or a slowing of the heart rate. These reactions may be brought on by pain or by strong emotions, such as fear or frustration. In some children, BHS may be related to iron deficiency anemia, a condition in which the body does not produce a normal number of red blood cells (3). There are two clinical types of breath holding spells, i.e., cyanotic

\section{Corresponding author:}

Dr. Abdelrahim A. Sadek, Pediatric Neurology Unit, Pediatric Department, Sohag University, Sohag, Egypt. Tel: +20.1065067057, Fax: +20.934602963, E-mail: abdoneurology@yahoo.com and wafaaderm78@yahoo.com Received: January 07, 2016, Accepted: March 17, 2016, Published: April 2016 iThenticate screening: March 17, 2016, English editing: April 01, 2016, Quality control: April 06, 2016 (c) 2016 The Authors. This is an open access article under the terms of the Creative Commons Attribution-NonCommercialNoDerivs License, which permits use and distribution in any medium, provided the original work is properly cited, the use is non-commercial and no modifications or adaptations are made. 
(blue) and pallid (pale) spells. BHS should be differentiated from epilepsy, congenital heart disease, vasovagal syncope, prolonged QT interval, and hyperactive carotid sinus. BHS is a clinical diagnosis. EEGs are not needed for diagnosis, but they are done sometimes, especially when the semiology of the disease is unclear. The interictal EEG is normal. If a breath-holding spell is captured on an EEG, initially there is a slowing of the EEG's background. As the child become bradycardic, further slowing and suppression of the EEG's background become apparent at the time subsequent or concomitant asystole. As the child regains consciousness, there is a rapid return of the EEG's background to normal (4). It is not known exactly how ID causes breath-holding spells, but it has been proposed that iron has a role in catecholamine metabolism and in the functioning of enzymes and neurotransmitters in the central nervous system. Iron has an important role in the regulation of neurologic functions, and it may reduce the level of monoamine oxidase in the brain and since this enzyme regulates many brain activities, a deficiency may have adverse effects on the brain's functions (5).

\section{Material and Methods}

This study was a descriptive, hospital-based study done in the Neuropediatric Outpatient Clinic at Sohag University Hospital over a one-year period. All children who presented with breath holding spells during the study period were included in the study. The diagnosis of BHS was made clinically by a pediatrician based on the history given by the children's mothers and on the personal observation of the spells. A "spell" was defined as the stoppage of the child's breathing during expiration after a deep inspiration while crying. The spells were classified into cyanotic and pallid spells. The study was approved by the Research Ethics Committee at Sohag Faculty of Medicine, and verbal consent was obtained from the children's guardians. The study was conducted in accordance with The Code of Ethics of the World Medical Association (Declaration of Helsinki) for experiments involving humans. A detailed history was taken for each patient included in the study, and a thorough clinical examination was conducted with special emphasis on the patient's personal history, including age and gender, complaint (i.e., type of BHS, its duration and the provoking factors), family history of similar conditions and consanguinity, and developmental history. The following laboratory investigations were conducted for the studied group: 1- complete blood count (CBC) was done by Abbott Cell Dyn Ruby analyzer, Abbott Diagnostic, Abbott Park, IL, USA; 2- serum ferritin (normal ferritin ranges from 6-60 ng/ml; 3- serum iron (normal serum iron in children ranges from 37-145 $\mu \mathrm{g} / \mathrm{dL}$; 4- total iron binding capacity (normal TIBC ranges from $250-350 \mu \mathrm{g} / \mathrm{dL}$; electroencephalogram (EEG) was done for all eligible patients. Clinical, laboratory, and EEG data were entered into the SPSS software package, version 10, for descriptive statistics. The results of the study were expressed as mean with standard deviation and range for continuous variables and as percentages for discrete variables.

\section{Results}

During the period of study (one year), 32 children were diagnosed with breath holding spells by clinical and laboratory evaluation in the Neuropediatric Outpatients' Clinic at Sohag University Hospital. The mean age was 19.95 months with an age range from four months to four years. Concerning the gender distribution, 19 of the children were males (59\%), and 13 were females (41\%) (Table 1).

Table 1. Characteristics of the studied children

\begin{tabular}{|l|l|l|}
\hline Characteristics & Summary statistics \\
\hline Age (months); Mean \pm SD & & $19.95 \pm 12.17$ \\
\hline Gender; n (\%) & Female & $13(40.63)$ \\
\cline { 2 - 3 } & Male & $19(59.38)$ \\
\hline \multirow{2}{*}{ Type of HBS; n (\%) } & Cyanotic & $23(71.88)$ \\
\cline { 2 - 3 } & Pallide & $9(28.13)$ \\
\hline \multirow{3}{*}{ Provocating factors } & Anger & $1(3.13)$ \\
\cline { 2 - 3 } & Anger \& crying & $4(12.5)$ \\
\cline { 2 - 3 } & Crying & $27(84.38)$ \\
\hline \multicolumn{2}{|l|}{ Duration in minutes; Mean \pm SD } & $3.74 \pm 3.34$ \\
\hline
\end{tabular}

Concerning the type of BHS of the studied children, 23 of them had cyanotic BHS (71.88\%), and nine of them had pallide BHS (28.13\%). Provocating factors were crying in 27 patients $(84.38 \%)$, anger and crying in four patients $(12.50 \%)$, and anger only in one patient $(3.13 \%)$. The duration of the spells ranged from 0.17 to 15 minutes (mean 3.74 minutes) (Table 1). Delayed motor milestones were noted in six patients (18.75\%). Delayed speech was noted in 21 patients (34.38\%) (Table 2). A family history of similar condition was present in 10 patients (31.25\%) and a 
history of consanguinity was present in 17 patients (53.13\%) (Table 2). Iron deficiency anemia was observed in 20 patients $(62.5 \%)$ as detected by low hemoglobin concentration $(\mathrm{Hb})$, low hematocrite value (HCT), low mean corpuscular volume (MCV), low mean corpuscular hemoglobin $(\mathrm{MCH})$, low serum iron, low serum ferritin, and high total iron binding capacity (TIBC). The mean $\mathrm{Hb}$ concentration was $10.24 \mathrm{~g} / \mathrm{dl}$, and it ranged from 8.5 to 12.5 $\mathrm{g} / \mathrm{dl}$. Mean hematocrite value was 33.40, and it ranged from 28 to 39.6. Mean MCV was $70.09 \mathrm{fl}$, and the range was from 51.80 to $86.40 \mathrm{fl}$. The mean MCH was $21.72 \mathrm{pg} / \mathrm{ml}$, and it ranged from 14.90 to $28.90 \mathrm{pg} / \mathrm{ml}$. Mean serum ferritin was $12.27 \mathrm{ng} / \mathrm{ml}$, and it ranged from 2.21 to $77.40 \mathrm{ng} / \mathrm{ml}$. Mean serum iron was $52.75 \mu \mathrm{g} / \mathrm{dL}$, and it ranged from 21 to $100 \mu \mathrm{g} / \mathrm{dL}$. Mean iron binding capacity was $340.47 \mu \mathrm{g} / \mathrm{dL}$, and it ranged from 200 to $440 \mu \mathrm{g} / \mathrm{dL}$ (Table $3)$. EEG was normal in 11 patients $(34.38 \%)$ and abnormal in 21 patients $(65.63 \%)$. Abnormalities that were detected were focal epileptic discharge in 20 patients $(62.5 \%)$ and generalized cerebral dysrhythemia in one patient $(3.13 \%)$.

Table 2. Developmental history and family history of the studied patients

\begin{tabular}{|l|l|l|}
\hline Characteristics & Summary statistics \\
\hline Language development; $\mathrm{n}(\%)$ & Normal & $11(65.63)$ \\
\cline { 2 - 3 } & Delayed & $21(34.38)$ \\
\hline \multirow{2}{*}{ Motor development; $\mathbf{n}(\%)$} & Normal & $26(81.25)$ \\
\cline { 2 - 3 } & Delayed & $6(18.75)$ \\
\hline Family history; n (\%) & No & $22(68.75)$ \\
\cline { 2 - 3 } & Yes & $10(31.25)$ \\
\hline \multirow{2}{*}{ Consanguinity } & No & $15(46.88)$ \\
\cline { 2 - 3 } & Yes & $17(53.13)$ \\
\hline
\end{tabular}

Table 3. Laboratory investigations of studied children

\begin{tabular}{|l|l|}
\hline Test & Mean \pm SD \\
\hline HB & $10.24 \pm 1.13$ \\
\hline HCT & $33.4 \pm 3.48$ \\
\hline MCV & $70.09 \pm 7.43$ \\
\hline MCH & $21.72 \pm 3.23$ \\
\hline Serum iron & $52.75 \pm 34.43$ \\
\hline Serum ferritin & $12.72 \pm 15.32$ \\
\hline Iron binding capacity & $340.47 \pm 75.42$ \\
\hline
\end{tabular}

\section{Discussion}

In this study, we performed a clinical and laboratory analysis of the data of 32 children that had BHS. We focused on determining the type of BHS and its relationship with iron deficiency anemia, with special consideration for the presence of abnormal EEG findings and the analysis of neurodevelopmental status. Diagnosis of BHS was made clinically by a pediatrician based on the history given by the mothers and personal observation of the spells. Spells were defined as the child's breathing stopping during expiration after a deep inspiration while crying. Anemia was evaluated by CBC, serum ferritin, serum iron, and total iron binding capacity (TIBC). The mean age of the studied patients was 19.95 months with an age range from four months to four years, which was in good agreement with several other studies (4, 6-8). However, in a study done by Olsen (9), the age onset range was between six and 24 months, but cases with onset in the neonatal period and as late as 48 months have been described. In a study by Tonekaboni et al. (10), the ages of most of the patients $(66 \%)$ were between six and 24 months. In a study by Subbarayan et al. (11), $40 \%$ of the patients had the onset of BHS within first six months of life, $23.3 \%$ of them had onset between seven and 12 months of age, and $26.7 \%$ had their first experience between 13 and 24 months. The onset of BHS after two years of age constituted only $10 \%$. Concerning the gender of the studied children, $59 \%$ were males, and $41 \%$ were females. BHS were observed more frequently in boys than in girls, and this also has been reported in other studies $(6,12,13)$. Concerning the type of BHS of the children that were studied, cyanotic BHS was detected in $71.88 \%$, and these results also were in good agreement with other studies $(7,14)$. However, these results were lower than that of some other studies, e.g., Anil et al. (13) (94\%), Bhatia et al. (15) (96\%), and Tonekaboni et al. (10) (88.5\%). However, in a study done by Zehetner et al. (16), 49/95 (51\%) had cyanotic spells, $27 / 95$ (29\%) only had pallid spells, and 19/95 (20\%) had both types with one predominating over the other. A provocating factor was noticed in all patients. Crying was the most common triggering factor $(84.38 \%)$, similar to the study of Bhatia et al. (15) in which anger and frustration were the common triggering factors in $90.0 \%$ of the 
cases. In Ashrafi et al.'s study (7), anger and pain were the common triggering factors (65.1\%). Other studies reported that BHS was provoked by frustration, anger, fear, or pain, i.e., Goraya et al. (17), Daoud et al. (18), and Evans Owen (19). Consanguinity was present in $53.13 \%$ of patients, and these results were much higher than those of Ashrafi et al.'s study (7) (30\%) or Hilal Mocan et al.'s study (20) (8.7\%). This can be explained by the fact that relatives often marry in the high ranges in our country, especially in Upper Egypt where our study was conducted. In a study done by Daoud et al. (18), positive consanguinity was detected in $70 \%$ of the studied cases. Concerning family history, a positive family history was present in $31.25 \%$, which was in agreement with many several similar studies, e.g., Paul et al. (14) (35\%), Zehetner et al. (16) (30\%), and Bhat et al. (12) (34\%) . However, it was less than those of Ashrafi et al.'s (7) study (51.2\%) and Daoud et al.'s study (18) (47.5\%). However, in the study done by Handan Gençgonül et al. (8), positive family history was detected in $22 \%$ of the studied cases. Family pedigree analysis of children with BHS suggested an autosomal dominant pattern of inheritance with reduced penetration (7). In a study conducted in the Hartford Center in the USA, family pedigrees of 57 proband were examined, of which $27 \%$ of proband parents and $21 \%$ of proband siblings had severe current or prior BHS.

Iron deficiency anemia was observed in $62.5 \%$ of the studied patients, as detected by low Hb, low HCT, low MCV, low $\mathrm{MCH}$, low serum iron, low serum ferritin, and high total iron binding capacity (TIBC), and these results were in good agreement with those of Tonekaboni et al. (10) (68.6\%) and Hudagolu et al. (4) (62.5\%). The mechanism that links BHS and IDA is not clear. It has been postulated that decreased oxygen concentrations in the lungs (1) and in the brain (15) in IDA caused BHS. It has been proposed that iron has an important role in the regulation of the neurologic function, it may reduce the monoamine oxidase in the brain by increasing the urinary norepinephrine, and since this enzyme regulates many brain activities, its deficiency may have an adverse effect on brain function (5). This result was slightly higher than that of Ashrafi et al. (7) (53\%) and that of Handan Gençgonül et al. (8) $(56 \%)$. This can be explained by low socioeconomic status and bad nutritional habits, especially at time of weaning, and the lack of iron supplements. But our results were lower than those of Hilal Mocan et al. (20) (69.2\%). This can be explained by the marked improvement of formula production in the last few years. Most types of formula are enriched with iron and vitamins. As reported previously, a low serum ferritin may be the earliest laboratory finding of IDA (18). Concerning the EEG findings, the EEGs were normal in (34.38\%) of the studied patients and abnormal in $(65.63 \%)$ of them. The abnormalities that were detected were focal mild epileptic discharge in 20 patients $(62.5 \%)$ and generalized cerebral dysrhythemia in one patient (3.13\%). In a study by Hudagolu et al. (4), 37.5\% had epileptogenic EEG abnormalities, $12.5 \%$ had benign EEG variants, and (50\%) had completely normal EEGs. The focal epileptiform discharge that was detected in the patients originated from the centrotemporal and centroparietal regions. There was no statistically significant difference between patients with epileptiform EEG changes and patients with normal EEGs. In Hilal Mocan et al.'s study, abnormal EEGs were detected in $20 \%$ of the studied patients in the form of slight or moderate EEG abnormalities (20). In the study done by Ashrafi et al., all of the patients had normal EEGs (7).

\section{Conclusions}

BHS is a common and important problem that is encountered in the Neuropediatric Clinic, and the cyanotic type was more common than the pallid type. BHS commonly was associated with iron deficiency anemia, which, in turn, is a common nutritional problem in our country. The EEGs showed significant abnormalities in this disorder.

\section{Acknowledgments:}

We thank the children who participated in this study and their parents for allowing them to participate.

\section{Conflict of Interest:}

There is no conflict of interest to be declared.

\section{Authors' contributions:}

All authors contributed to this project and article equally. All authors read and approved the final manuscript.

\section{References}

1) DiMario FJ Jr. Prospective Study of Children with Cyanotic and Pallid Breath-Holding Spells. Pediatrics. 2001; 107(2): 265-9. PMID: 11158456.

2) Anderson JE, Bluestone D. Breath-Holding Spells: Scary but not Serious. Contemp Pediatr. 2000; 1: 61.

3) Health wise. Breath holding spells, Incorporated, Boise, 2010; ID 83701. 
4) Hudagolu O, Dirik E, Yis U. Parental attitude of mothers, iron deficiency anemia, and breath-holding spells. Pediatr Neurol. 2006; 35: 18-20. doi: 10.1016/j.pediatrneurol.2005.12.006. PMID: 16814080.

5) Orri KE, Kato Z, Osamu F. Changes of autonomic nervous system function in patients with breath holding spells treated with iron. J Child Neurology. 2002; 17: 337-40. doi: 10.1177/088307380201700505.

6) Abbaskhanian A, Ehteshami S, Sajjadi S, Rezai MS. Effects of Piracetam on Pediatric Breath Holding Spells: A Randomized Double Blind Controlled Trial. Iran J Child Neurol. 2012; 6: 9-15. PMID: 24665274, PMCID: PMC3943019.

7) Ashrafi MR, Shajari H, Salajegheh N. Breath-holding spells: an analysis of 43 cases. Iran J Child Neurol. 2006; 2: 17-20.

8) Handan Gençgonül, Şükrü Cin, Nejat Akar, Gülhis Deda. Iron and zinc levels in breath holding spells. journal of Ankara medical school. 2002; 24: 56-96.

9) Olsen AL, Mathiasen R, Rasmussen NH, Knudsen FU. Long-term prognosis for children with breathholding spells. Dan Med Bull. 2010; 57(11): A4217. PMID: 21055373.

10) Tonekaboni SH, Alavi S, Mahvelati F, Tabasi Z. Effects of oral iron supplement on breath- holding spells in children. Iran J Child Neurol. 2006; 1: 33-7.

11) Subbarayan A, Ganesan B, Anbumani J. Temperamental traits of breath holding children: a case control study. Indian J Psychiatry. 2008; 50: 192-6. doi: 10.4103/0019-5545.43635. PMID: 19742234, PMCID: PMC2738355.

12) Bhat MA, Ali W, Mohidin K, Sultana M. Prospective study of severe breath holding spells and role of iron. India Journal of Pediatric Neurology. 2007; 5: 27-32.

13) Anil BG, Nedunchezian K, Jayanthini V, Pathmanabhan M. Breath Holding Spells: Evaluation of Autonomic Nervous System Function. Indian Pediatrics. 2005; 42: 923-7. PMID: 16208053.

14) Paul S, Matz MD. Breath-Holding Spells is a sample topic found in Pediatrics Central. Last updated 2009: October 26.

15) Bhatia MS, Singhal PK, Dhar NK, Nigam VR, Malik SC, Mullick DN. Breath-holding spells: an analysis of 50 cases. Indian Journal Pediatric. 1990; 27; 73-9.

16) Zehetner AA, Orr N, Buckmaster A, Williams K, Wheeler DM. Iron supplementation for breath-holding attacks in children. Cochrane Database Syst Rev. 2010; 5: 1578-605. doi: 10.1002/14651858.cd008132.pub2. PMID: 20464763.

17) Goraya JS, Virdi VS. Persistence of breath holding spells into late childhood. J Child Neurol. 2001; 16: 697-8. doi: 10.1177/088307380101600916. PMID: 11575615.

18) Daoud AS, Batieha A, Al-Sheyyab M, Ebuekteish F, Hijazi S. Effectiveness of iron therapy on breathholding spells. J Pediatr. 1997; 130: 547-50. doi: 10.1016/S0022-3476(97)70237-3. PMID: 9108851.

19) Evans Owen B. Breath holding spells. Pediatric Annals. 1997; 26: 7. doi: 10.3928/0090-4481-1997070105 .

20) Hilal Mocan, Alisan Yildiran, Fazil Orhan, Erol Erduran. Breath holding spells in 91 children and response to treatment with iron. Arch Dis Child. 1999; 81: 261-2. doi: 10.1136/adc.81.3.261. PMID: 10451402, PMCID: PMC1718051. 